\title{
A Unique Approach to Retain Dentures in a Patient with Hypohidrotic Ectodermal Dysplasia
}

\section{Anand K Tavargeri ${ }^{1 *}$, Satyabodh S Guttal ${ }^{2}$, Garima Jain ${ }^{3}$, Shruti Patil', Rajesh Anegundi ${ }^{2}$, Vijay Trasad ${ }^{1}$ and Prashanth Battepatti ${ }^{1}$}

${ }^{1}$ Department of Pedodontics, SDM College of Dental Sciences and Hospital, Dharwad, Karnataka, India

${ }^{2}$ Department of Prosthodontics, SDM College of Dental Sciences and Hospital, Dharwad, Karnataka, India

${ }^{3}$ Uttaranchal Dental and Medical Research Institute, Dehradun, Uttarakhand, India

\begin{abstract}
Ectodermal dysplasia is a large complex group of disorders resulting in abnormal development of two or more ectodermal structures. Oral manifestations include partial or complete anodontia and poor bony bases affecting aesthetics and function. Dental management in such patients is difficult and requires intervention throughout the growth period of the patient, until a definitive treatment is rendered. This case report describes the prosthetic rehabilitation of a young patient with total anodontia, which is a rare event in contrast to partial anodontia. A unique approach was devised to improve the retention and stability of compromised ridges. Conventional dentures were delivered to the patient with like-pole magnets incorporated in the occlusal surface of posterior denture teeth of upper and lower denture facing correspondingly which resulted in repulsive force. This enhanced retention and stability of the dentures.
\end{abstract}

Keywords: Ectodermal dysplasia; Complete denture; Magnets

\section{Introduction}

Ectodermal Dysplasia (ED) is a large, complex group of clinical and genetic disorders defined by the abnormal development of two or more ectodermal structures. The condition is marked by a developmental deficiency of hair, sweat glands, nails, teeth, and other ectodermal structures. Even though by some accounts more than 170 different subtypes of ED can be defined, the two most commonly encountered types in this group are Hypohidrotic and Hidrotic ED [1]

The oral manifestations are partial or complete anodontia and poor bony foundation which impairs both aesthetic as well as the masticatory function. Difficulty in mastication may cause nutritional problems [2]. The absence of teeth affects the facial appearance which may affect normal social and psychological development in these young patients. Therefore, dental care for ED patient becomes an important concern for rehabilitation of dentition for proper function and for overall emotional well-being and social progress of the patient. The prevalence of ED is 7 cases out of 10,000 births [3]. Dental rehabilitation of patients with such dysplastic condition necessitates a multidisciplinary approach. However, the definitive treatment can only be imparted after cessation of growth. In order to enhance the aesthetic and functional requirements, however, a provisional treatment can be rendered. There are very few reports in the literature with respect to edentulous pediatric ED. To render a provisional treatment for an edentulous pediatric ED patient is challenging. Presented here is a case report of an edentulous 13-year old boy with hypohidrotic ED.

\section{Case Report}

A 13-year-lustreless old boy visited the Department of Pedodontics and Preventive Dentistry with the chief complaint of missing teeth since childhood, causing difficulty in eating and speech. The parents reported that the child never had teeth in his mouth. The child was diagnosed with ectodermal dysplasia by his attending pediatrician. The general medical history and family history was non-contributory. On examination, the child was moderately built and exhibited classical features of hypohidrotic ED: anodontia, hypohidrosis, sparse lusterless hair on the scalp, scarce eyebrows and eyelashes, dark pigmentation around periorbital area, frontal bossing, dry and scaly skin, reduced vertical facial height and protuberant lips (Figure 1).

Intraoral examination showed edentulous upper and lower arches
(Figures $2 \mathrm{a}$ and $2 \mathrm{~b}$ ). The ridges were atrophied, reduced both in height and width for his age. The mucosa was slightly dry. Tongue was enlarged. The absence of teeth was confirmed with an orthopantomograph which showed absence of tooth buds (Figure 2c).

Considering the age of the patient, provisional complete dentures were planned till completion of growth. The compromised ridges would affect the stability and retention of dentures. To enhance the retention and stability, a unique approach using magnets on posterior denture teeth on both the upper and lower prosthesis was planned.

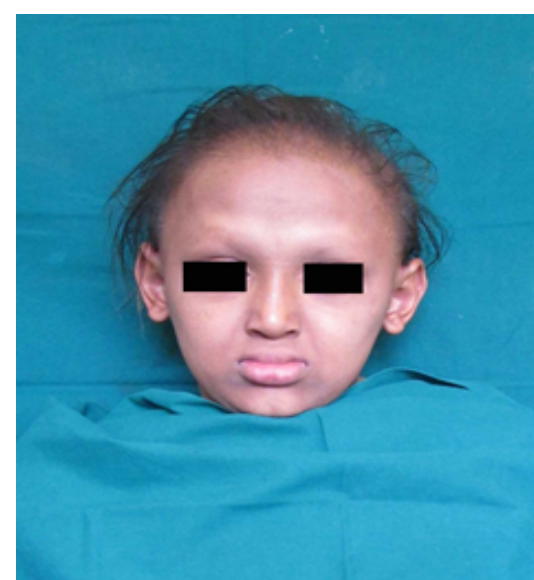

Figure 1: Patient presented classical features of ectodermal dysplasia.

*Corresponding author: Dr. Anand Tavargeri, MDS, Professor and Head Department of Pedodontics, SDM College of Dental Sciences and Hospital, Dharwad, Karnataka 580009, India, Tel: +91 9886242451; Fax: +91 8362467612 E-mail: anandtavargeri@yahoo.com

Received December 22, 2015; Accepted February 12, 2016; Published February 19, 2016

Citation: Tavargeri AK, Guttal SS, Jain G, Patil S, Anegundi R, et al. (2016) A Unique Approach to Retain Dentures in a Patient with Hypohidrotic Ectodermal Dysplasia. Dentistry 6: 362. doi:10.4172/2161-1122.1000362

Copyright: (C) 2016 Tavargeri AK, et al. This is an open-access article distributed under the terms of the Creative Commons Attribution License, which permits unrestricted use, distribution, and reproduction in any medium, provided the original author and source are credited. 


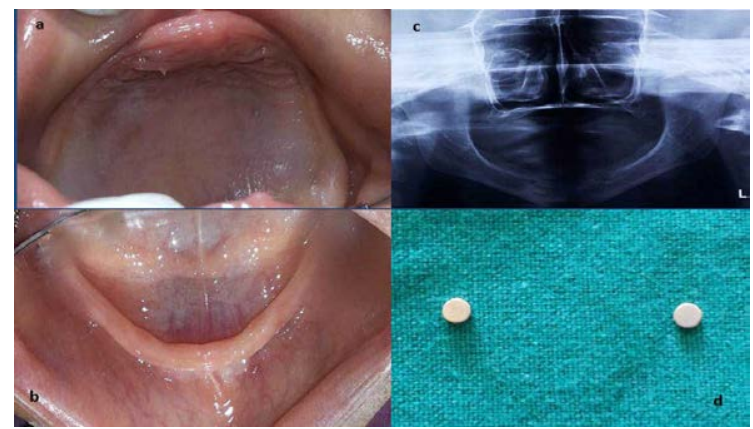

a. Reduced maxillary arch bone; b. Mandibular arch resembling a resorbed geriatric arch; c. Bone height revealed on OPG; d. Magnets used in the dentures

Figure 2: Intra oral view and magnets used for the treatment.

Preliminary impressions were made using impression compound (Y-Dent, Germany) and diagnostic casts were obtained. The undercuts were blocked with wax (Y-Dent, Germany). Custom trays were fabricated using cold cure acrylic resin (Hindustan Dental Products; Hyderabad, India) with $2 \mathrm{~mm}$ of wax spacer. Border moulding was performed using green stick compound (DPI, Mumbai, India) for both maxillary and mandibular arches. The final impression was obtained using zinc oxide eugenol impression paste (DPI, Mumbai, India) for maxillary arch and regular body vinyl polysiloxane (Dentsply, USA) for mandibular arch. Mandibular arch was more compromised in terms of resorption therefore vinyl polysiloxane was used to make the mandibular impression, since it records finer tissue details. The final master cast was obtained using Type III gypsum (Kalastone, Kalabhai Pvt Ltd, Mumbai, India).

The denture base was fabricated on the master cast using cold cure acrylic and occlusion rims were prepared using modelling wax. Jaw relations were established. The recorded jaw relation was mounted on a mean value articulator. Small sized teeth (Acryrock, Ruthinium Dental Products, Italy) were selected for the patient for optimum esthetics and function. Teeth arrangement was done. Magnets (Magnetech Engg; Mumbai, India) approximately with a $4 \mathrm{~mm}$ diameter and 2 $\mathrm{mm}$ thickness were selected. Small circular slots corresponding to the dimensions of the magnet (Figure $2 \mathrm{~d}$ ) were made on the occlusal surfaces of denture premolar and molar teeth in both the arches using a straight fissure bur. The magnets were oriented on the upper and lower posterior teeth in such a way that the like poles of the magnets faced each other. They were placed using self-cure acrylic resin. The like poles would generate a repulsive force and help in retaining the dentures in place. The try in was performed and patient acceptability and centric relation was checked. After the try in, the magnets were removed and the space was filled with pattern resin (Pattern, GC Dental Products, Japan). The dentures were processed using heat polymerized acrylic resin. After retrieving from flasks they were trimmed, finished and polished and magnets were replaced back into prepared slots using chemically polymerized acrylic resin (Figures $3 \mathrm{a}$ and $3 \mathrm{~b}$ ). Denture insertion was done and post insertion instructions were given regarding the diet and maintenance of denture (Figures $3 \mathrm{c}$ and $3 \mathrm{~d}$ ).

The patient was asked to report for a regular follow-up after 2 days, 1 week, 2 weeks and 3 months for adjustments and trimming of the denture. The patient and his parents were explained the limitation of the provisional dentures, and that they may have to report repeatedly for replacement of dentures as per the growth of the jaws. The dentures were well accepted by the patient with improved mastication. The magnets provided good retention resulting in better acceptability. The child showed increase in weight and improved social interactions in school with increased participation in extracurricular activities.

\section{Discussion}

Treatment of a pediatric patient with ED is a challenging task. Children with ED usually have a normal mentality and life expectancy, and their facial appearance demands professional concern for their well-being and social progress. Oral rehabilitation is required even before skeletal and dental maturation has occurred. ED may affect normal social and psychological development in young patients. Literature shows children rejected by their peer groups are more likely to become aggressive and may experience mental health problems in adulthood [4]. Functional needs also must be considered as these children experience difficulty in mastication which hampers their general health. Therefore, dental care for ED patient becomes challenging and necessary.

According to Nowak, a series of introductory visits may be needed before the actual treatment commences. This is essential to attain the required patient trust, compliance and conditioning to increase the acceptability of the appliance by the pediatric patient. The initial investment in few introductory visits will improve the dentist-patient relationship and at the same time prepare the patient for acceptance of subsequent multiple appointments and replacement of appliances later $[5,6]$. Thus, management of patient with ED needs a multidisciplinary approach. The clinician needs to be astute, knowledgeable in growth and development, behavioral management, techniques in the fabrication of prosthesis, the ability to motivate the patient and parent in the use of the prosthesis, and the long-term follow-up for the modification and/ or replacement of the prosthesis. This restores the patient's appearance and helps them in the development of positive self-image.

Hypodontia or anodontia is associated with lack of development of the alveolar ridges and results in less volume of bone for support of a conventional prosthesis. The prosthetic rehabilitation of a patient with ED involves conventional complete dentures (age appropriate) and implant supported complete dentures. Because of early age intervention and the need to frequently modify the intraoral prosthesis during rapid growth periods, a removable partial denture or complete denture prosthesis is indicated initially [7]. However, removable partial denture has certain complications like increased caries rate, periodontal complications, and increased residual alveolar resorption.

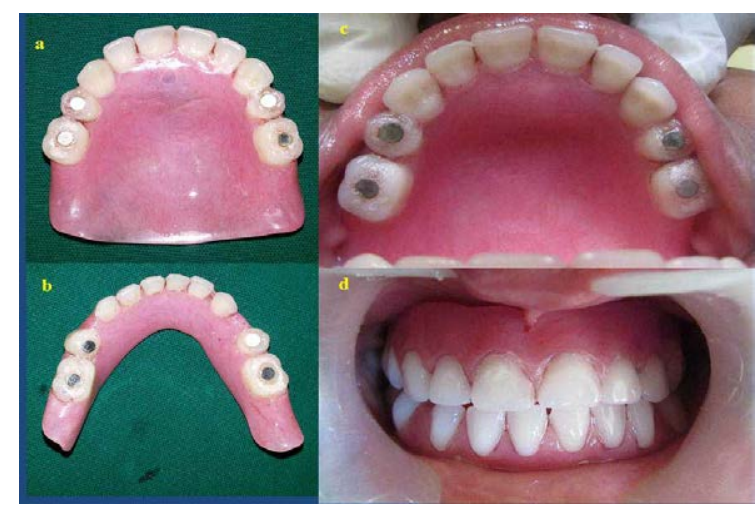

a. Maxillary denture with magnets embedded; b. Mandibular denture with magnets; c. Placement of maxillary denture; d. Depicting perfect occlusion

Figure 3: Dentures fabricated and placed in the oral cavity. 
Citation: Tavargeri AK, Guttal SS, Jain G, Patil S, Anegundi R, et al. (2016) A Unique Approach to Retain Dentures in a Patient with Hypohidrotic Ectodermal Dysplasia. Dentistry 6: 362. doi:10.4172/2161-1122.1000362

Dental implants for children are a new treatment modality [8]. The published reports about implant use in young patients are very limited, and long-term clinical studies are necessary for sound conclusions. There are two primary concerns. First, if implants are present during several years of facial growth, there is a danger of them becoming embedded, relocated, or displaced as the jaw grows. The second area of concern is the effect of prosthesis on growth. Osseointegrated implants behave like ankylosed teeth, arresting both eruption and alveolar bone growth and not adapting to changes secondary to alveolar bone growth [9]. Thus, it is recommended to wait for the completion of skeletal and dental growth before planning to place an implant. Whenever possible, implant placement must be delayed until the age of 15 years for girls and 18 years for boys [10]. The average time required for the placement of the complete dentures is two weeks and thereafter follow-up initially twice in a week for a month and later once in six months.

The use of conventional prostheses before placing implants is encouraged, since it helps to condition the growing patient and provides esthetic and functional information for the subsequent implant treatment plan [11]. It is also important until the patient achieves a more appropriate level of maturity.

In the present case, due to the boy's young age, on-going development of the jaws and insufficient quantity of alveolar bone, application of removable dentures may be the only restorative option for this patient for now. The bone height and width was not sufficient for implant insertion. Conventional dentures were planned. The ridges were compromised which would affect the stability and retention of dentures. To enhance the retention and stability, a unique approach using magnets on occlusal surface of posterior denture teeth on both the upper and lower prosthesis was planned with like poles facing each other. Generally magnets are used to get attraction type retention where the magnet in the denture attracts to the keeper cemented in the remaining roots. Age appropriate conventional dentures improve masticatory function; provide good denture stability and retention with psychological satisfaction and esthetics. Magnets are utilized in prosthodontics to enhance the retention of dentures. The retention achieved surpasses that of conventional dentures. The laboratory procedures are relatively easy. It is easily accepted by the patient $[12,13]$.

This case report presents a distinctive treatment plan where the magnets were utilized to generate the repulsive force thereby the upper and lower dentures were pushed against each other to firmly adhere the ridges. The patient was comfortable with the denture retention. The increased social activity at school was the testimony for this statement. The patient is on a follow up and subsequently may require replacements with new magnets after a period of 25 months since, the magnets may corrode and lose the power in spite being coated. Even if the frequent servicing of the dentures may be considered as the one of the limitation, but the benefits of magnet usage outweigh its limitations.

\section{Conclusion}

Young patients with ectodermal dysplasia need early identification and evaluation by a dental professional to determine the oral ramifications of the condition. Appropriate care and multidisciplinary approach needs to be rendered throughout the child's growth cycle to maintain oral function, address the aesthetic needs of the patient and fulfill social and psychological needs.

\section{References}

1. Shigli A, Reddy RP, Hugar SM, Deshpande D (2005) Hypohidrotic ectodermal dysplasia: a unique approach to esthetic and prosthetic management: a case report. J Indian Soc Pedod Prev Dent 23: 31-34.

2. Pigno MA, Blackrnan RB, Cronin RJ Jr, Cavazos E (1996) Prosthodontic management of ectodermal dysplasia: A review of the literature. $\mathrm{J}$ Prosthet Dent 76: 541-545.

3. Anuroopa A, Abdulla J, Lovely M (2013) Oral rehabilitation of a young patien with hypohidrotic ectodermal dysplasia: A clinical report. Contemp Clin Dent 3: S33-S36.

4. Shah R, Shah S (2014) Oral rehabilitation of a patient with ectodermal dysplasia: A multidisciplinary approach. J Nat Sci Bio Med 5: 462-466.

5. Tarjan I, Gabris K, Rozsa N (2005) Early prosthetic treatment of patients with ectodermal dysplasia: a clinical report. J Prosthet Dent 93: 419-424.

6. Nowak AJ (1988) Dental treatment for patients with ectodermal dysplasias. Birth Defects Orig Artic Ser 24: 243-252.

7. Singh T, Singh R, Singh GP, Singh JP (2013) Hypohidrotic ectoderma dysplasia: a felicitous approach to esthetic and prosthetic management. Int $\mathrm{J}$ Clin Pediatr Dent 6: 140-145.

8. Percinoto C, Vieira AE, Barbieri CM, Melhado FL, Moreira KS (2001) Use of dental implants in children: a literature review. Quintessence Int 32: 381-383.

9. Chaudhary N, Ahwalat B, Kumar A, Vijaylaxmy, Goel P (2015) Implants in paedodontics: A puzzled corner. Indian J Sci Res 6: 193-197.

10. Mishra SK, Chowdhary N, Chowdhary R (2013) Dental implants in growing children. J Indian Soc Pedod Prev Dent 31: 3-9.

11. Shah A, Latoo S, Lone S, Khan M, Bhagat RK, et al. (2011) Anhidrotic ectodermal dysplasia: report of two cases and review of literature. Indian J Dent Sci 2: 29-35

12. Kamath R, Sarandha DL, Anand M (2011) Clinical use of magnets in prosthodontics. Int J Clin Dent Sci 2: 10-14.

13. Rockman RA, Hall KB, Fiebiger M (2007) Magnetic retention of dental prosthesis in a child with ectodermal dysplasia. J Am Dent Assoc 138: 610-615. 